http://dx.doi.org/10.30681/23588403v13i0210

\title{
PARTIGIANO, PORTAMI VIA: ANÁlISES SOBRE A ATRIBUIÇÃO DE SENTIDO À PALAVRA ATRAVÉS DA HISTÓRIA E DAS ARTES
}

Data de recebimento: $16 / 12 / 2019$

Aceite: 15/02/2020

\section{Mike Ceriani de Oliveira Gomes ${ }^{1}$}

\begin{abstract}
Resumo: Este estudo tem por finalidade analisar as representações linguísticas na atuação de grupos políticos enquanto antagonistas a ascensões de governos e governantes com tendências fascistas. Tomou-se como objeto de estudo o substantivo-adjetivo italiano partigiano, sendo este muitas vezes representado em obras artísticas de autores com tendências à simpatia pelo movimento partigiano. A partir da influência da série espanhola La Casa de Papel, que, por sua vez, aumentou a popularidade da clássica canção italiana Bella Ciao, também é analisada a forma como partigiano foi se traduzindo em outros idiomas, de acordo com o contexto histórico de seus respectivos países, bem como sua interpretação pode variar dentro do próprio idioma italiano. Como fechamento, é levantada uma breve observação acerca da utilização do substantivo-adjetivo resistência, assumindo a mesma função de partigiano, porém, na atualidade.
\end{abstract}

Palavras-chave: Grupos políticos; Artes; Resistência.

\begin{abstract}
This study aims to analyze the linguistic representations on the performance of political groups as antagonists to the rise of fascist governments and rulers. The object of study was taken by the Italian adjective-noun partigiano, which is often represented in artistic works by authors with a tendency towards sympathy for the partigiano movement. Through the influence of the Spanish series La Casa de Papel, which increased the popularity of the classic Italian song Bella Ciao, it is also analyzed how partigiano was translated into other languages, according to the historical context of their respective countries as well as their interpretation may vary within the Italian language. As a conclusion, a brief observation is raised about the use of the adjective-noun resistance, assuming the same function as partigiano, however, at present.
\end{abstract}

Keywords: Political groups; Arts; Resistance.

\section{Introdução}

Diversas áreas das Ciências Humanas em ambiente escolar muitas vezes contam com intervenções interdisciplinares em suas elaborações. Nas aulas de Idiomas, Geografia e

\footnotetext{
${ }^{1}$ Especialista em Metodologia do Ensino da Língua Inglesa (2019) pelo Instituto Pedagógico de Minas Gerais (IPEMIG). E-mail: mikegd1@ @otmail.com
} 
História, músicas, filmes e séries vêm se revelando potenciais objetos didáticos na prática do ensino e da exploração científica de processos pedagógicos.

Em exemplo ao exposto, através de um artigo sobre a canção "Cálice", de Chico Buarque, Nascimento (2017) aponta a capacidade da música enquanto objeto de protesto político, bem como sua articulação eficaz no ato de transmitir mensagens implícitas à sua produção. Isso pode ocorrer porque a música traz consigo mensagens, e muitas mensagens trazem consigo sentido à língua.

Como define Meksenas (2014, p. 71), a linguagem é a forma como são transmitidos conhecimentos, ideias, valores, em outras palavras, é a soma dos recursos que permite aos seres vivos a divulgação de informações. Há então uma questão situacional que orienta o estudo das raízes da linguística, sua história, seu contexto social.

Prova disso é a força que a clássica canção italiana Bella Ciao passa a retomar enquanto reproduzida pela série espanhola La Casa de Papel, lançada em 2018. O veículo BBC (2018) relembra o vínculo da canção à História Italiana, como esta se tornou um hino de resistência antifascista por décadas e como a série reforça seu sentido e didaticamente o transmite ao público.

O veículo de comunicação ainda reforça na canção em questão um uso estratégico do substantivo e adjetivo da língua italiana partigiano e, com ele, sua convergência com o enredo da série em termos de produção de sentido, ou seja, como uma palavra, ainda que não apresente uma tradução específica, pode carregar consigo uma ideia.

Mediante o relato, este artigo visa analisar o sentido apropriado à palavra partidiano a partir de trechos selecionados de três canções cujas letras foram escritas na língua italiana, sendo elas: Il partigiano John, do grupo italiano Modena City Ramblers, L'italiano (Lasciatemi cantare), do cantor italiano Toto Cutugno e Bella Ciao (artista anônimo), dando foco à última a fim de contextualizar com a série e, posteriormente, sua exposição enquanto objeto de protesto.

\section{Il partigiano: a resistência italiana}

A enciclopédia italiana Treccani (2019), define-se como partigiano "Membro de formações irregulares armadas que atuam em uma área ocupada pelo inimigo, exercendo ações perturbadoras e de guerrilha”. Por outro lado, algumas atribuições dadas a partigiano não necessariamente remetem a membros da luta armada. 
De acordo com o Dicionário Escolar WMF (2013, p. 274), o substantivo também pode ser definido por "partidário" ou "partidário do desarmamento", embora não haja uma tradução literal para o termo em questão.

O próprio WMF (2013, p. 295) não compreende a tradução acima na modalidade Português-Italiano, sendo partidário(a):

- Adjetivo: seguace, sostenitore(trice);

- Adjetivo-substantivo masculino: 1 (simpatizante) simpatizzante 2 (sectário) settario(a), fazioso(sa).

A parte de tais definições, Vaccaro (2010, p. 261) por diversas vezes recorre ao substantivo-adjetivo "Resistência" com a finalidade de criar uma linha de correlação com o substantivo-adjetivo partigiano em seu uso prático.

Mastrogregori (2008, p. 31), em duas citações sobre o termo, lhe atribui o sentido de oposição política, no caso ao partido italiano Democracia Cristã, fundada pelo ex-Primeiro Ministro Alcide de Gasperi e de orientação centro-direita.

Sem impor qualquer tradução ou definição específica, Paiva Neto (2013, p. 8) relata a luta de grupos partigiani no processo de libertação da ocupação de tropas nazifascistas na Itália a partir do ano de 1944.

Meireles et al. (2016, p. 114) lembra que, neste período histórico, o grupo contava com a nomenclatura de Resistenza Partigiana - ou Resistência Italiana, para o Português, não atribuindo, portanto, uma tradução específica ao vocábulo.

Frente ao exposto, pode-se ter como compreensão do vocábulo partigiano um soldado, membro de grupo que se opõe politicamente às ideologias de extrema-direita, ainda que, segundo Meireles et al. (2016, p. 114-115) estes possam compor várias frentes ideológicas, mesmo anarquistas, comunistas, liberais, socialistas, as frentes de defesa dos interesses da classe trabalhadora, etc.

\section{Bella Ciao}

Não há uma constatação histórica sobre os primeiros registros de Bella Ciao, embora seja conhecimento de que seus primeiros cânticos tenham sido entoados, a princípio, ao final 
do século XIX por camponesas italianas na região da Padânia (centro e norte da Itália) enquanto realizavam suas atividades no campo.

Também foi responsável por criar e difundir entre os partigiani a música da resistência, 'Bella Ciao'. Originalmente criada por camponesas colhedoras de arroz da região da Padânia e depois adaptada na Primeira Guerra Mundial, a nova versão criada pelo PCI ficou conhecida como símbolo da Resistência e, por isso, até hoje entoada em vários outros países e em momentos significativos na história da sociedade italiana. (MEIRELES et al., 2016, p. 116)

Vaccaro (2010, p. 261) salienta que, como forma de protesto, a canção foi entoada primeiramente em Nápoles, em 24 de agosto de 1918, no fim da primeira guerra mundial, o que tinha por finalidade ser um coro de resistência. Neste aspecto, a ideia de resistência já se nota em todo o conceito filosófico desta canção.

Vaccaro (2010, p. 262) complementa que já na primavera de 1944, a canção é passa a ser reproduzida em outra versão - a qual passa a ganhar popularidade - na comuna italiana Bolonha, se estendendo depois a todo o território italiano até o fim da primeira guerra.

Como já se sabe, seu aspecto foi no período antagônico à ocupação nazifascista em território italiano e, como será relatada abaixo, a linguagem representada na letra reflete claramente seu caráter ideológico de resistência, reforçando o sentido de partigiano.

\author{
Una mattina mi son svegliato \\ O bella ciao, bella ciao, bella ciao ciao ciao \\ Una mattina mi son svegliato \\ E ho trovato l'invasor
}

Neste trecho, o autor relata acordar pela manhã ( $m i$ son svegliato) e, em alusão à invasão nazifascista na Itália diz que encontrou um invasor ( $E$ ho trovato l'invasor). Sua posição passa a ganhar mais forma na segunda estrofe:

O partigiano portami via

O bella ciao, bella ciao, bella ciao ciao ciao

O partigiano portami via

Che mi sento di morir 
A referência ao grupo partigiano neste trecho é denotada a intenção de integrá-lo (partigiano, portami via), mesmo que ingressar à luta custe sua vida (Che mi sento di morir). A predisposição para lutar até as últimas consequências fica mais clara na terceira estrofe:

E se io muoio da partigiano

O bella ciao, bella ciao, bella ciao ciao ciao

E se io muoio da partigiano

Tu mi devi seppellir

É relatada a consciência de que participar da resistência pode custar sua vida pelo uso da oração subordinativa condicional "se", que assume as mesmas funções em português (se eu morro) e em italiano (se io muoio). "E se eu morro na condição de partigiano, você deve me enterrar" - E se io muoio da partigiano, tu mi devi seppellir.

\section{L'italiano}

A canção L'italiano, também conhecida por Lasciatemi Cantare, escrita e interpretada pelo cantor Toto Cutugno (1983), se apropria do adjetivo partigiano apenas uma vez, em sua segunda estrofe. Aparentemente ela apenas trata positivamente os costumes e tradições italianas, mas junto a toda a alegria de falar sobre um povo, a mesma estrofe pode apresentar uma interpretação à parte disso, se considerado o contexto político histórico italiano da época.

Buongiorno Italia, gli spaghetti al dente

$\mathrm{E}$ un partigiano come presidente

Con l'autoradio sempre nella mano destra

Un canarino sopra la finestra

Seguindo a tradução de L'italiano através do site brasileiro de letras de música Vagalume, este trecho fica:

Bom dia Itália do espaguete ao dente

E um guerrilheiro como presidente 
Com o radio do carro sempre na mão direita

E um canarinho em cima da janela

No trecho em questão, o tradutor compreende partigiano como guerrilheiro, mas o que chama a atenção, não é a tradução deste adjetivo, mas o fato de que em 1983, ano em que a canção foi a público, a Itália tinha como sétimo presidente (1978-1985) o socialista Alessandro Pertini (1896-1990), membro da resistência italiana contra os avanços fascistas, eleito com a maior porcentagem de votos sobre o sistema eleitoral italiano desde o início do período presidencialista até o atual presidente, Sérgio Mattarella (2015).

\section{Il partigiano John}

A canção interpretada pelo grupo Modena City Ramblers, em 1996, tem como principal inspiração a obra Il Partigiano Johnny, de Beppe Fenoglio (1922-1963). Esta obra trata a vida de Johnny, idealista e membro da resistência armada durante a luta contra a invasão nazista na Itália em 1943.

E' qui

E' quel passato che affiora

son scatti di rabbia e tensione, non regge più

John lo sa,

ha settant'anni e tornerà

ad abbracciare il suo fucile

se deve andrà

è un partigiano e lotterà

c'è pietà?

Conforme a livre tradução:

Está aqui

Esse passado está mostrando

Um ataque de raiva e tensão, ele não aguenta mais

John sabe 
Ele tem 70 anos e ele vai pegar seu rifle novamente

Se ele precisar, ele irá

Ele é partigiano e luta

Há piedade?

Esta estrofe pode, claramente, representar alguns dos pontos mais característicos - e até certo ponto, estereotipados - dos membros integrados aos grupos da luta armada italiana, atuantes em ações contra as invasões nazistas na antiga Itália fascista de Benito Mussolini, nos anos quarenta.

O partigiano Johnny, como se pode ver nesta canção, reúne os atributos do guerrilheiro idealista que, mesmo com o passar do tempo, não se desvincula de suas convicções, e se necessário, pega em armas para defendê-las.

\section{Considerações finais}

A popularização do substantivo-adjetivo italiano partigiano após 2017, pela canção Bella Ciao, através da série La Casa de Papel, evidencia uma relação direta entre a linguagem e a produção artística, mais do que tudo, a forma como esta passa a ganhar uma gama de sentidos, variantes de acordo com a realidade de pessoas ou grupos que passam a adotar um determinado vocabulário.

Entoar a canção Bella Ciao como forma de protesto contra governos e governantes compreendidos como autoritários e fascistas traz novos caminhos também para a compreensão do manifesto artístico enquanto ferramenta de luta social e de integração de povos com ideais em comum, ainda que com divergências em diversos outros aspectos, a exemplo da formação da resistência italiana nos anos quarenta.

No que tange à formação desses grupos, assim como aponta a pesquisa, o termo partigiano torna-se a raiz mais fidedigna para o termo Resistência, que adotam os grupos que se opõem a esses governos. Assim como partigiano, Resistência passa a ganhar, igualmente, a ideia oposição às ascensões fascistas, por mais amplo e diversificado que seja o seu significado na língua portuguesa.

\section{Referências}


AFRICA UNITE. Letras. Compositor: Africa Unite. Disponível em: https://www.letras.mus.br/africa-unite/409409/. Acessado em 27 de novembro de 2019. ANÔNIMO. Vagalume. Compositor: Anônimo. Disponível em: https://www.vagalume.com.br/rats/bella-ciao.html. Acessado em 24 de novembro de 2019. BBC. A história por trás de 'Bella Ciao', hino dos protagonistas de 'La Casa de Papel'. 2018. Acesso: https://www.bbc.com/portuguese/geral-43934601. Acessado em 22 de novembro de 2019.

COTUGNO, Toto. Vagalume. Compositor: Toto Cotugno, 1983. Disponível em: https://www.vagalume.com.br/toto-cutugno/litaliano-traducao.html. Acessado em 26 de novembro de 2019.

MEKSENAS, Paulo. Sociologia da educação: Introdução ao estudo da escola no processo de transformação social. 17 ed. São Paulo: Edições Loyola, 2014.

MASTROGREGORI, Massimo. O eclipse da nação (1940-1945). IEA-USP Estudos avançados. v. 22 n. 62, 2008, p. 29-54.

MEIRELES, Ricardo da Silva; MORAES, Cíntia da Silva. ECOS DA RESISTÊNCIA EM O PEQUENO PRÍNCIPE, DE ANTOINE DE SAINT-EXUPÉRY, E A TRILHA DOS NINHOS DE ARANHA, DE ÍTALO CALVINO. Litterata. v. 2, n. 6, 2016, p. 103-123.

MODENA CITY RAMBLERS. Vagalume. Compositor: $M$

NASCIMENTO, Rayene Maria do. ATOS DE FALA NA MÚSICA CÁliCE: REALIZAÇÕES, EFEITOS E CONSEGUÊNCIAS. Revista de Estudos Acadêmicos de Letras. v. 10, n. 2, 2017, p. 37-44.

PAIVA NETO, Francisco Fagundes de. Biografia e política: D. Luigi Grassi e a resistência ao fascismo na Diocese de Alba (Cuneo/Itália). XXVII Simpósio Nacional de História: Conhecimento histórico e diálogo social. 2013, p. 1-15.

PARTIDÁRIO. In: DICIONÁRIO ESCOLAR WMF. São Paulo: Editora WMF Martins Fontes, 2013.

PARTIGIANO. In: DICIONÁRIO ESCOLAR WMF. São Paulo: Editora WMF Martins Fontes, 2013.

TRECCANI. Partigiano. 2019. Acesso: http://www.treccani.it/enciclopedia/partigiano/. Acessado em 01 de dezembro de 2019.

VACCARO, Giulio. EL SOL DEL PORVENIR: LA CANCIÓN EN LA RESISTENCIA ITALIANA. Revista Literatura em Debate. v. 4, n. 6, 2010, p. 259-278. 